\title{
Effects of Depression on Aspects of Self-Care in Type 2 Diabetes
}

\author{
Richard Seides* \\ College of Nursing, Seton Hall University, South Orange, USA \\ Email: ${ }^{*}$ richard.seides@shu.edu
}

Received 20 April 2014; revised 3 June 2014; accepted 18 June 2014

Copyright (C) 2014 by author and Scientific Research Publishing Inc.

This work is licensed under the Creative Commons Attribution International License (CC BY).

http://creativecommons.org/licenses/by/4.0/

\section{(c) (i) Open Access}

\begin{abstract}
Aims and Objectives: Depression is common among patients with chronic medical illnesses. The impact of depressive symptoms in patients with type 2 diabetes on self-care and glycosylated hemoglobin (HbA1c) was explored. Background: Depression is known to decrease compliance with most medical regimens. This study investigated depression's effects on different aspects of compliance with a diabetic regimen. Design: Cross-sectional, correlational, quantitative study. Methods: A cross-sectional study was conducted using data from 126 patients with type 2 diabetes from a diabetes education class. Participants completed depression and self-care inventories. Regression analyses were performed to determine the impact of depressive symptoms on the dependent variables of compliance to diabetes self-care and HbA1c levels. Results: Levels of depression were significantly and inversely correlated with 1) total self-care scores, accounting for $\mathbf{5 . 1 \%}$ of the variance, 2) compliance with glucose self-monitoring accounting for $3.4 \%$ of the variance, and 3) compliance with diet accounting for $9.3 \%$ of the variance. Levels of depression were not significantly related to HbA1c. Conclusions: Depressive symptoms are associated with poorer total self-care, poorer glucose self-monitoring, and poorer dietary compliance in type 2 diabetes patients. Depression scores help explain variations in patients' performance with aspects of compliance to diabetes management. Relevance to clinical practice: Administering a personality questionnaire, perhaps on the initial visit could enable the clinical to know which aspects of diabetes self-care are affected by depression, which would enable the clinician to more closely monitor melancholic patients in the effort to improve glycemic control and medical outcomes.
\end{abstract}

\section{Keywords}

Diabetes, Depression, Compliance, Adherence, HbA1c, Diet, Exercise, Glucose Self-Monitoring

${ }^{*}$ Corresponding author. 


\section{Introduction}

The risk of depression in patients with diabetes is approximately double compared with those without diabetes [1] [2]. Prevalence of depression among patients with diabetes ranges from $8 \%$ to $15 \%$, compared with an estimate of only $3 \%$ to $4 \%$ in the general population [1] [3] [4]. Approximately 20\% of diabetes patients suffer clinically significant symptoms [5]. Type 2 diabetes patients with comorbid depression have a significant increase in mortality [6] [7]. Depression also increases the risk of poor glycemic control and diabetes complications [8] [9].

\section{Background/Literature}

\subsection{Depression and Diabetes}

Diabetes self-care and compliance may be impaired in the presence of depression. Depression is a risk factor for noncompliance to medical treatment in other chronic diseases; depressed patients having a three-fold increase in noncompliance compared to non-depressed patients [10] [11]. Depression is associated with poorer compliance with exercise [12], diet [13] [14], glucose self-monitoring, and medications [15] [16].

Depressed patients may be at increased risk for developing type 2 diabetes. Studies have found that depression is linked to the development of type 2 diabetes [17]-[22], because of the relationship between depression and a sedentary lifestyle [23] [24] and intake of fat-laden foods, which contribute to obesity [21] [25]-[27]. Additionally, neuroendocrine changes such as increased cortisol and catecholamine levels can lead to insulin resistance and the development of diabetes [28]-[30]. A question is whether depression can result from having diabetes. Depression can indeed arise from dealing with the challenges of living with diabetes [31] [32]. A bidirectional quality to this relationship exists, which provides important reasons to further study this public health problem.

The prognosis and community costs of comorbid depression and diabetes are often difficult to precisely discern. The prognoses for both diabetes and depression, are worse when they are comorbid than when they exist alone [33]-[35]. Similarly, the costs increase when diabetes and depression are comorbid. Due to the significant prevalence of coexisting depression and diabetes, the identification of relationships between them can help clinicians predict poor outcomes with type 2 diabetes, as discussed in the next section.

\subsection{Depression Adversely Affects Self-Care}

In order to live a nearly normal lifespan, the diabetes patient needs to diligently and persistently perform the daily tasks of blood glucose self-monitoring, adhere to dietary restrictions, exercise regularly, and take medications. Doing so can achieve optimal levels of HbA1c and reduce the risk of serious complications. The presence of depression often severely diminishes the patients' ability to perform these daily self-care responsibilities, which leads to worsening of glycemic control [13] [36] [37].

In a study of 4000 diabetes patients, depression was associated with poor compliance with oral medications, even in patients with acceptable HbA1c levels before the start of the study [38]. Numerous studies suggest depression is associated with poorer HbA1c [6] [39] [40] [41]. It is reasonable to conclude that depression would have a negative impact on self-care, and consequently lead to more advanced disease and increased comorbidities.

The literature is consistent, stating that depressed diabetes patients do not comply well with diet, exercise and medications [12] [13] [15] [38]. The investigators measured compliance with the following instruments: the Hopkins Symptom Checklist-90, the Patient Health Questionnaire, the SDSCA, the Short-Form 12 Health Survey (a generic measure of health status), a measure of self-reported diabetes-related complications from retinopathy, nephropathy, and peripheral neuropathy, pharmacy refill data to determine medication adherence, as well as objective blood work to measure HbA1c and serum lipids. Patients with diabetes are likely to fail to engage in self-care on a regular basis, leading to decreased diabetes control and increased risk of comorbidities. Depression leads to poorer glycemic control in diabetes patients, as well as poor compliance in patients with many other chronic diseases.

This report details findings of the predictability of compliance with specific aspects of type 2 diabetes regimens with and without depression as a predictor variable to determine if depression can predict compliance over and above the control variables of age, gender, ethnicity, disease duration, and medication status. 


\section{Research Hypothesis}

Scores on the Center for Epidemiological Studies Depression Scale (CES-D) will predict a statistically significant portion of the variance in compliance as assessed by SDSCA subscale scores and in HbA1c when age, gender, ethnicity, medication status, and duration of diabetes are statistically controlled.

\section{Research Design and Methods}

\subsection{Design}

This quantitative correlational study used a convenience sample in a cross-sectional design to discover relationships between measures of depression and measures of HbA1c and self-care. Regression analyses included the control variables of age, ethnicity, gender, disease duration, and medication status.

\subsection{Data Collection Procedures}

Data were collected on a total of 126 participants enrolled in a diabetes education class at a public suburban hospital in New Jersey. The requirement for inclusion in the study was that the participants have type 2 diabetes for at least three months, as newly diagnosed patients have no history of compliance behavior. Exclusion criteria were pregnancy and severe cognitive impairment, such as an inability to read the questionnaires. No exclusions were made based on age, gender, income, ethnicity, or medication status. The study was explained to attendees at the conclusion of their diabetes nutrition education lesson. Most attendees were of middle class economic status with private insurance. Each participant was given a \$10 honorarium upon completion of the surveys.

\subsection{Participants}

The study population was diverse (See Table 1). Income levels ranged from below $\$ 20,000$ to over $\$ 80,000$.

Table 1. Demographic characteristics of participants.

\begin{tabular}{|c|c|c|}
\hline Characteristic & $\mathrm{N}$ & $\%$ \\
\hline \multicolumn{3}{|l|}{ Age at time of survey (years) } \\
\hline $20-29$ & 1 & 0.8 \\
\hline $30-39$ & 13 & 10.3 \\
\hline $40-49$ & 14 & 11.1 \\
\hline $50-59$ & 33 & 26.2 \\
\hline $60-69$ & 32 & 25.4 \\
\hline $70-79$ & 24 & 19.1 \\
\hline $80-89$ & 9 & 7.1 \\
\hline \multicolumn{3}{|l|}{ Disease duration } \\
\hline Diagnosed within one year & 34 & 27 \\
\hline Diagnosed 1 - 4 years & 30 & 23.8 \\
\hline Diagnosed 4 - 12 years & 29 & 23 \\
\hline Diagnosed 12+ years & 33 & 26.2 \\
\hline \multicolumn{3}{|l|}{ Ethnicity } \\
\hline African-American & 23 & 18.3 \\
\hline Hispanic & 20 & 15.9 \\
\hline Caucasian & 76 & 60.3 \\
\hline Asian or Pacific Islander & 5 & 4 \\
\hline Native American & 2 & 1.6 \\
\hline \multicolumn{3}{|l|}{ Gender } \\
\hline Male & 52 & 41 \\
\hline Female & 74 & 59 \\
\hline \multicolumn{3}{|l|}{ Medication status } \\
\hline Pills only & 76 & 60.3 \\
\hline Injections only & 13 & 10.4 \\
\hline Pills and injections & 37 & 29.3 \\
\hline
\end{tabular}


Ages were from 27 to 85, with a mean of 59.6 years. Approximately $75 \%$ of participants were diagnosed during the past 12 years; the average duration of diabetes was 7.5 years. The participants were on one of three medical regimens to treat their diabetes: oral hypoglycemic agents (pills), a combination of oral agents and insulin injections, or insulin injections only.

\subsection{Instruments}

The Summary of Diabetes Self-Care Activities (SDSCA). The SDSCA (Toobert, et al., 2000) is probably the most widely used self-report tool for evaluating diabetes self-care in adults [42]. This study used an abbreviated 11-item version of the SDSCA self-report measure of the frequency of performing diabetes self-care tasks over the preceding seven days. Areas assessed include diet, exercise, glucose monitoring, medication taking, foot care, and smoking. The brevity of the revised SDSCA and its ease of scoring make it practical and useful in clinical and research settings. Use of this shorter revised instrument has provided valuable information on norms, reliability, and validity [43].

CES-D. The CES-D was developed by the Center for Epidemiologic Studies at the National Institutes of Mental Health to meet the need for a concise, economical measure of depression suitable for use in community surveys. The CES-D consists of 20 items. The CES-D assesses mood, somatic complaints, interactions with others, and motor function. The final score has a range from 0 to 60 , and this single total score is used as an estimate of the degree of depressive symptoms, with a higher score indicating greater impairment. People with an overall score of 16 or higher have been found to have major depressive disorders.

Demographic and Diabetes History Measure. A six-item questionnaire elicited information on participants' gender, age, ethnicity, income, medication status, and year of diabetes diagnosis.

HbA1c. HbA1c is a form of hemoglobin used primarily to identify the average serum glucose concentration over the preceding three months. Normal levels of glucose produce a normal amount of glycosylated hemoglobin. As the average amount of plasma glucose increases, the fraction of glycosylated hemoglobin increases. HbA1c served as an objective surrogate marker of glycemic control. As in previous studies, glycemic control was used as a measure of compliance [44] [45].

\subsection{Data Analysis}

Statistical tests were conducted in the following way: Correlations of each SDSCA factor, the CES-D total score, and HbA1c were determined. Significant zero-order correlations between HbA1c, SDSCA, and CES-D scores were reevaluated using multiple regression analysis with statistical controls for the effects of age, ethnicity, gender, disease duration, and medication status.

Hierarchical regression analysis was performed in the following manner. First, all control variables (age, gender, disease duration, African American and other races, and injections and pills and injections only) were placed into a multiple regression model with each of the dependent variables of interest-Total SDSCA, Total General Diet, Total Specific Diet, Exercise, Glucose Monitoring, Foot Care, and HbA1c. R-squared, a value whose main purpose is the prediction of future outcomes on the basis of other related information was then evaluated. Second, the depression variable was added to each of the models to discern whether the addition of depression made a difference in the ability to predict the dependent variable. In other words, it was determined if there was a statistically significant difference in the value of R-square when examining the models with and the models without depression, when regressing each of the dependent variables.

\section{Results}

Participant demographics and Pearson correlations conducted using all demographic and surveyed variables and HbA1c levels, can be seen in Table 1 and Table 2. Significant correlations were found between Depression and Total SDSCA scores and depression and Total General Diet score. No statistically significant correlation was found between Depression and HbA1c or with the other subscales of the SCSDA.

\subsection{Total SDSCA}

The discovery of a statistically significant bivariate correlation between depression and the Total SDSCA score $(r=-0.247, p=0.005)$ suggests that participants scoring higher on the CES-D depression scale were less com- 


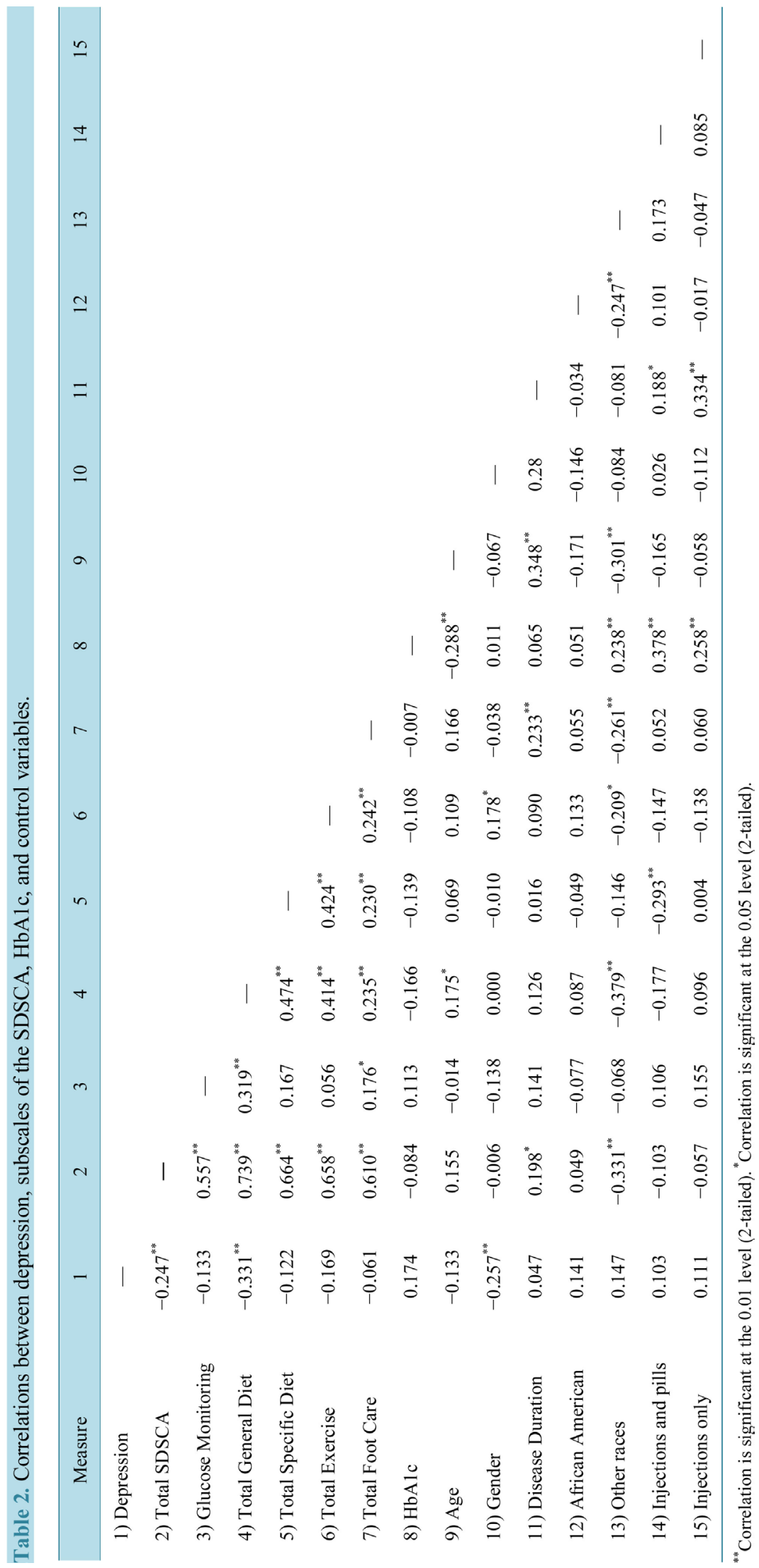


pliant with their multi-faceted diabetes regimen that included diet, exercise, daily self glucose monitoring, and foot care. Moreover, hierarchical regression disclosed a statistically significant difference in the R-square values when depression was added to the model (See Table 3). The depression coefficient was significant $(B=-0.283$, $p=0.007$ ), indicating that depression improved the ability to predict Total SDSCA scores over and above the control variables. The full model accounted for $20 \%$ of the variance in Total SDSCA scores, with depression accounting for $5.1 \%$ of the variance.

\subsection{Glucose Self-Monitoring}

The correlation between Glucose Monitoring scores and depression scores was not statistically significant $(\mathrm{r}=$ $-0.133, p=0.138$ ) without the control variables. Hierarchical regression disclosed a statistically significant difference in the R-square values when depression was added to the model regressing glucose monitoring on depression (See Table 3). The depression coefficient was negative and significant $(\mathrm{B}=-0.079, p=0.035$ ), indicating that depression adversely affects self-monitoring of serum glucose and that its addition to the model improved the ability to predict how well the participants monitored their blood sugar as prescribed. The full model accounted for $12.6 \%$ of the variance in glucose self-monitoring, with depression accounting for $3.4 \%$ of the variance.

\subsection{Total General Diet}

A significant bivariate correlation between depression and the Total General Diet score $(r=-0.331, p \leq 0.001)$ suggests that depression adversely affects compliance with dietary restrictions. Moreover, hierarchical regression disclosed a statistically significant difference in the R-square values when depression was added to the model regressing Total General Diet on depression and the control variables. The depression coefficient in this model was statistically significant $(\mathrm{B}=-0.113, p<0.001)$, indicating that the addition of depression improved the ability to predict how well the participants followed their diets. The full model accounted for $25.5 \%$ of the variance of Total General Diet scores, while depression explained 9.3\% of the variance.

Table 3. Hierarchical regression analysis summary for depression predicting compliance.

\begin{tabular}{|c|c|c|c|}
\hline Variable & $\mathrm{R}^{2}$ & $\Delta \mathrm{R}^{2}$ & $p($ of $\Delta \mathrm{F})$ \\
\hline \multicolumn{4}{|l|}{ Total SDSCA } \\
\hline Model $1^{*}$ & 0.149 & & \\
\hline Model $2^{* *}$ & 0.200 & 0.051 & 0.007 \\
\hline \multicolumn{4}{|c|}{ Glucose Monitoring } \\
\hline Model $1^{*}$ & 0.092 & & \\
\hline Model $2^{* *}$ & 0.126 & 0.034 & 0.035 \\
\hline \multicolumn{4}{|c|}{ Total General Diet } \\
\hline Model $1^{*}$ & 0.162 & & \\
\hline Model $2^{* *}$ & 0.255 & 0.093 & $<0.001$ \\
\hline \multicolumn{4}{|c|}{ Total Specific Diet } \\
\hline Model $1^{*}$ & 0.104 & & \\
\hline Model $2^{* *}$ & 0.111 & 0.008 & 0.315 \\
\hline \multicolumn{4}{|l|}{ Total Exercise } \\
\hline Model $1^{*}$ & 0.137 & & \\
\hline Model $2^{* *}$ & 0.148 & 0.011 & 0.217 \\
\hline \multicolumn{4}{|c|}{ Total Foot Care } \\
\hline Model $1^{*}$ & 0.123 & & \\
\hline Model $2^{* *}$ & 0.125 & 0.003 & 0.544 \\
\hline \multicolumn{4}{|l|}{ HbA1c } \\
\hline Model $1^{*}$ & 0.257 & & \\
\hline Model $2^{* *}$ & 0.264 & 0.008 & 0.275 \\
\hline
\end{tabular}

${ }^{*}$ Model with all control variables; ${ }^{* *}$ Model with all control variables plus depression. 
The addition of the depression variable to the models for Total Specific Diet, Total Foot, Total Exercise, and HbA1c did not improve the models. The R-square values comparing the models with and without the depression variable were not significantly different, indicating that the addition of depression did not improve the predictive quality of the models, as can be seen in Table 3 .

\section{Discussion}

This report examined relationships between depressive symptoms and compliance with type 2 diabetes regimens. Self-reported lower levels of self-care with increased depression found in this study are consistent with the literature, which showed that depressed mood can adversely affect cognition and compliance [13] [16] [46]. This study found that participants with depressive symptoms reported lower aggregate levels of compliance with diet, exercise, glucose self-monitoring, and foot care (the Total SDSCA score). Lower compliance levels in patients with depressive symptoms may be explained by an increased sense of helplessness and hopelessness, which serves to impede behavior, including self-care behavior.

In this study, depressed patients reported significantly fewer days of compliance with glucose self-monitoring regimens [47]. The clinical consequences of failing to measure serum glucose levels on a regular basis include giving the healthcare provider limited or wrong information regarding the efficacy of the medication regimen and/or impeding dietary recommendations, with resultant suboptimal medical treatment.

Participants with higher depression scores reported lower rates of eating healthfully. This finding is consistent with the discovery of Gonzalez, et al. [48], and found lower adherence to prescribed diet among diabetes patients with depression. Since poor diet is intimately associated with weight gain, higher medical risk, and poorer diabetes outcomes, this finding has important clinical relevance.

Unlike other studies in the literature, this study did not show that depressive symptoms significantly affect the remaining aspects of diabetes self-care that the SDSCA measures, i.e., total exercise, total foot care, and total specific diet. Total exercise questions asked if the participants exercised everyday and for how long. Participants' responses were not negatively affected by depressive symptoms. It could be expected that depression would adversely affect exercise patterns, but this phenomenon was not found. Participants' recall may have been imperfect or they did not want to admit to not exercising as prescribed, or they wanted to present themselves in a more positive light.

Foot care questions asked whether they checked their feet and inspected in between their toes. Respondents who were depressed did not answer these questions significantly differently from those who were not depressed. It is possible that whether depression exists or not, patients do not inspect their feet as often as recommended.

Depression did not significantly affect HbA1c levels over and above the other variables. The phenomenon of depression not having a significant deleterious effect on HbA1c is supported in the literature [12] [49] [50]. However, the literature is contradictory suggesting that depressive symptoms can negatively affect serum glucose levels [9] [13] [51].

Different measures of depression were used in these studies. When we compare different studies that use different instruments to measure a particular construct, different results are frequently obtained. Interestingly, the results from two different studies by Ciechanowski on depressive symptoms and diabetes yielded conflicting results [12] [13]. The same measure of depression, the Hopkins Symptom Checklist-90 (HSC-90) was used in both studies, however, psychological instruments are not a precise measure, and asking the same questions, even of the same person at different times on the same day, is likely to reveal different answers, leading to different study results.

\section{Conclusions}

This study has identified that depressive symptoms negatively affect dietary and glucose self-monitoring aspects of diabetes care, as well as overall diabetes self-care. Additionally, depression did not predict HbA1c. Given depression's prevalence and the harm that it can cause, recognition of depression's negative effects on energy level, concentration, and compliance as well as acknowledgment of effective programs, counseling and/or pharmacotherapeutics, to manage depression may improve compliance and clinical outcomes.

Due to potential negative health consequences associated with comorbid diabetes and depression, both conditions should be treated to maximize outcomes. Further research to investigate the relationships between depressive symptoms and diabetes may uncover heretofore poorly understood mechanisms. Improved knowledge of 
patients’ behavior affords the clinician the opportunity to intervene as appropriate to improve medical outcomes.

\section{Relevance of Clinical Practice}

With the myriad of health care advances in recent years, patient noncompliance remains medicine's Achilles heel. Clinicians can correctly predict whether a patient will comply with the medical regimen no greater than 50\% of the time. To decrease such impediments to optimal care, knowledge of patients' likelihood to comply is extremely valuable. This study supports the clinical significance of increased knowledge of patients' behavioral tendencies. As depression is widely acknowledged to decrease compliance, its identification could lead to altered therapeutic regimens such that the depressed patient will more likely comply. Improved clinical outcomes are apt to result.

\section{Acknowledgements}

The author gratefully acknowledges the expert assistance of Dr. Mike Abrams, PhD, ABPP, and Dr. Alexander Nussbaum, PhD.

\section{References}

[1] Anderson, R.J., Freedland, K.E., Clouse, R.E. and Lustman, P.J. (2001) The Prevalence of Comorbid Depression in Adults with Diabetes: A Meta-Analysis. Diabetes Care, 24, 1069-1078. http://dx.doi.org/10.2337/diacare.24.6.1069

[2] Mohamad, R., Abdul Kadir, A. and Yaacob, L.H. (2012) A Study on Depression among Patients with Type 2 Diabetes Mellitus in North-Eastcoast Malaysia. International Journal of Collaborative Research on Internal Medicine \& Public Health, 4, 1589-1600.

[3] Talbot, F. and Nouwen, A. (2000) A Review of the Relationship between Depression and Diabetes in Adults: Is There a Link? Diabetes Care, 23, 1556-1562. http://dx.doi.org/10.2337/diacare.23.10.1556

[4] Mathew, C.S., Dominic, M., Isaac, R. and Jacob, J.J. (2012) Prevalence of Depression in Consecutive Patients with Type 2 Diabetes Mellitus of 5-Year Duration and Its Impact on Glycemic Control. Indian Journal of Endocrinology and Metabolism, 16, 764-768. http://dx.doi.org/10.4103/2230-8210.100671

[5] Ali, S., Stone, M., Peters, J., Davies, M.J. and Khunti, K. (2006) The Prevalence of Co-Morbid Depression in Adults with Type 2 Diabetes: A Systematic Review and Meta-Analysis. Diabetes Medicine, 23, 1165-1173. http://dx.doi.org/10.1111/j.1464-5491.2006.01943.x

[6] Katon, W.J., Rutter, D., Simon, G., Lin, E.H., Ludman, E., Ciechanowski, P., Kinder, L., Young, B. and Won Korff, M. (2005) The Association of Comorbid Depression with Mortality in Patients with Type 2 Diabetes. Diabetes Care, 28, 2668-2670. http://dx.doi.org/10.2337/diacare.28.11.2668

[7] Lin, E.H.B., Heckbert, S.R., Rutter, C.M., Katon, W.J., Ciechanowski, P., Ludman, J., Oliver, M., Young, B.A., McCulloch, D.K. and Von Korff, M. (2009) Depression and Increased Mortality in Diabetes: Unexpected Causes of Death. Annals of Family Medicine, 7, 414-421. http://dx.doi.org/10.1370/afm.998

[8] de Groot, M., Anderson, R., Freedland, K.E., Clouse, R.E. and Lustman, P.J. (2001) Association of Depression and Diabetes Complications: A Meta-Analysis. Psychosomatic Medicine, 63, 619-630. http://dx.doi.org/10.1097/00006842-200107000-00015

[9] Lee, H., Chapa, D., Kao, C.W., Jones, D., Kapustin, J., Smith, J., Krichten, C., Donner, T., Thomas, S.A. and Friedmann, E. (2009) Depression, Quality of Life, and Glycemic Control in Individuals with Type 2 Diabetes. Journal of the American Academy of Nurse Practitioners, 21, 214-224. http://dx.doi.org/10.1111/j.1745-7599.2009.00396.x

[10] DiMatteo, M.R., Lepper, H.S. and Croghan, T.W. (2000) Depression Is a Risk Factor for Noncompliance with Medical Treatment Meta-Analysis of the Effects of Anxiety and Depression on Patient Adherence. Archives of Internal Medicine, 160, 2101-2107. http://dx.doi.org/10.1001/archinte.160.14.2101

[11] Grenard, J., Munjas, B., Adams, J., Suttorp, M., Maglione, M., McGlynn, M. and Gellad, W.F. (2011) Depression and Medication Adherence in the Treatment of Chronic Diseases in the United States: A Meta-Analysis. Journal of General Internal Medicine, 26, 1175-1182. http://dx.doi.org/10.1007/s11606-011-1704-y

[12] Ciechanowski, P.S., Katon, W.J., Russo, J.E. and Hirsch, I.B. (2003) The Relationship of Depressive Symptoms to Symptom Reporting, Self-Care and Glucose Control in Diabetes. General Hospital Psychiatry, 25, 246-252. http://dx.doi.org/10.1016/S0163-8343(03)00055-0

[13] Ciechanowski, P.S. (2000) Depression and Diabetes: Impact of Depressive Symptoms on Adherence, Function, and Costs. Archives of Internal Medicine, 160, 3278-3285. http://dx.doi.org/10.1001/archinte.160.21.3278

[14] Franks, M.M., Memphill, R.C., Seidel, A.J., Stephens, M.A.P., Rook, K.S. and Salem, J.K. (2012) Setbacks in Diet 
Adherence and Emotional Distress: A Study of Older Patients with Type 2 Diabetes and Their Spouses. Aging \& Mental Health, 16, 902-910. http://dx.doi.org/10.1080/13607863.2012.674486

[15] Lin, E.H., Katon, W., Von Korff, M., Rutter, C., Simon, G.E., Oliver, M., Ciechanowski, P., Ludman, E.J., Bush, T. and Young, B. (2004) Relationship of Depression and Diabetes Self-Care, Medication Adherence, and Preventative Care. Diabetes Care, 27, 2154-2160. http://dx.doi.org/10.2337/diacare.27.9.2154

[16] Bogner, H.R., Morales, K.H., De Vries, H.F. and Cappola, A.R. (2012) Integrated Management of Type 2 Diabetes Mellitus and Depression Treatment to Improve Medication Adherence: A Randomized Controlled Trial. Annals of Family Medicine, 10, 15-22. http://dx.doi.org/10.1370/afm.1344

[17] Campayo, A., De Jonge, P., Roy, J.F., Saz, P., De La Camara, J.R., Quintanilla, M.A., Marcos, G., Santaairbara, J. and Lobo, A. (2010) Depressive Disorder and Incident Diabetes Mellitus: The Effect of Characteristics of Depression. The American Journal of Psychiatry, 167, 580-588. http://dx.doi.org/10.1176/appi.ajp.2009.09010038

[18] Eaton, W.W., Armenian, H., Gallo, J., Pratt, L. and Ford, D.E. (1996) Depression and Risk for Onset of Type II Diabetes: A Prospective Population-Based Study. Diabetes Care, 19, 1097-1102. http://dx.doi.org/10.2337/diacare.19.10.1097

[19] Lustman, P.J. and Clouse, R.E. (2007) Depression in Diabetes: The Chicken or the Egg? Psychosomatic Medicine, 69, 297-299. http://dx.doi.org/10.1097/PSY.0b013e318060cc2d

[20] Mezuk, B., Eaton, W.W., Albrecht, S. and Golden, S.H. (2008) Depression and Type 2 Diabetes over the Lifespan: A Meta-Analysis. Diabetes Care, 31, 2383-2390. http://dx.doi.org/10.2337/dc08-0985

[21] Golden, S.H., Williams, J.E., Ford, D.E., Yeh, H.C., Paton, S., Nieto, F.J. and Brancati, F.L. (2004) Depressive Symptoms and the Risk of Type 2 Diabetes: The Atherosclerosis Risk in Communities Study. Diabetes Care, 27, 429-435. http://dx.doi.org/10.2337/diacare.27.2.429

[22] Engum, A. (2007) The Role of Depression and Anxiety in Onset of Diabetes in a Large Population-Based Study. Journal of Psychosomatic Research, 62, 31-38. http://dx.doi.org/10.1016/j.jpsychores.2006.07.009

[23] Manson, J., Rimm, E., Stampfer, M., Colditz, G.A., Willett, W.C., Krolewski, A.S., Rosner, B., Hennekens, C.H. and Speizer, F.E. (1991) Physical Activity and Incidence of Non-Insulin-Dependent Diabetes Mellitus in Women. Lancet, 338, 774-778. http://dx.doi.org/10.1016/0140-6736(91)90664-B

[24] Teychenne, M., Ball, K. and Salmon, J. (2010) Sedentary Behavior and Depression among Adults: A Review. International Journal of Behavioral Medicine, 17, 246-254. http://dx.doi.org/10.1007/s12529-010-9075-z

[25] Leea, S.H., Rodriguez, C.R. and Hong, K. (2011) High Fat Caloric Consumption and Low Levels of Physical Activity May Induce Prevalence of Obesity in Hispanic American Children. International Journal of Applied Sports Sciences, 23, 371-382.

[26] Palinkas, L.A., Lee, P.P. and Barrett-Connor, E. (2004) A Prospective Study of Type 2 Diabetes and Depressive Symptoms in the Elderly: The Rancho Bernardo Study. Diabetes Medicine, 21, 1185-1191. http://dx.doi.org/10.1111/j.1464-5491.2004.01315.x

[27] Hu, J., Amoako, E.P., Gruber, K.J. and Rossen, E.K. (2007) The Relationship among Health Functioning Indicators and Depression in Older Adults with Diabetes. Issues in Mental Health Nursing, 28, 133-150. http://dx.doi.org/10.1080/01612840601096305

[28] Lake, C.R., Pickar, D., Ziegler, M.G., Lipper, S., Slater, S. and Murphy, D.L. (1982) High Plasma Norepinephrine Levels in Patients with Major Affective Disorder. American Journal of Psychiatry, 139, 1315-1318.

[29] Winokur, A., Maislin, G., Phillips, J.L. and Amsterdam, J.D. (1988) Insulin Resistance after Oral Glucose Tolerance Testing in Patients with Major Depression. American Journal of Psychiatry, 145, 325-330.

[30] Sjostrand, M. and Eriksson, J.W. (2009) Neuroendocrine Mechanisms in Insulin Resistance. Molecular and Cellular Endocrinology, 297, 104-111. http://dx.doi.org/10.1016/j.mce.2008.05.010

[31] Talbot, F. and Nouwen, A. (2000) A Review of the Relationship between Depression and Diabetes in Adults: Is There a Link? Diabetes Care, 23, 1556-1562. http://dx.doi.org/10.2337/diacare.23.10.1556

[32] Roy, T. and Lloyd, C.E. (2012) Epidemiology of Depression and Diabetes: A Systematic Review. Journal of Affective Disorders, 142, S8-S21. http://dx.doi.org/10.1016/S0165-0327(12)70004-6

[33] Blay, S.L., Fillenbaum, G.G., Marinho, V., Andreoli, S.B. and Gastal, F.L. (2011) Increased Health Burden Associated with Comorbid Depression in Older Brazilians with Diabetes. Journal of Affective Disorders, 134, 77-84. http://dx.doi.org/10.1016/j.jad.2011.05.012

[34] Egede, L.E., Nietert, P.J. and Zheng, D. (2005) Depression and All-Cause and Coronary Heart Disease Mortality among Adults with and without Diabetes. Diabetes Care, 28, 1339-1345. http://dx.doi.org/10.2337/diacare.28.6.1339

[35] Katon, W., Lin, E.H.B. and Kroenke, K. (2007) The Association of Depression and Anxiety with Medical Symptom Burden in Patients with Chronic Medical Illness. General Hospital Psychiatry, 29, 147-155. 
http://dx.doi.org/10.1016/j.genhosppsych.2006.11.005

[36] Egede, L.E., Ellis, C. and Grubaugh, A.L. (2009) The Effect of Depression on Self-Care Behaviors and Quality of Care in a National Sample of Adults with Diabetes. General Hospital Psychiatry, 31, 422-427. http://dx.doi.org/10.1016/j.genhosppsych.2009.06.007

[37] Hampson, S., Glasgow, R. and Strycker, L. (2000) Beliefs versus Feelings: A Comparison of Personal Models and Depression for Predicting Multiple Outcomes in Diabetes. British Journal of Health Psychology, 5, 27-40. http://dx.doi.org/10.1348/135910700168748

[38] Katon, W.J., Russo, J.E., Heckbert, S.R., Lin, E.H.B., Ciechanowski, P., Ludman, E., Young, B. and Von Korff, M. (2009) The Relationship between Changes in Depression Symptoms and Changes in Health Risk Behaviors in Patients with Diabetes. International Journal of Geriatric Psychiatry, 25, 466-475. http://dx.doi.org/10.1002/gps.2363

[39] Lustman, P.J., Anderson, R.J., Freedland, K.E., De Groot, M., Carney, R.M. and Clouse, R.E. (2000) Depression and Poor Glycemic Control: A Meta-Analytic Review of the Literature. Diabetes Care, 23, 934-942. http://dx.doi.org/10.2337/diacare.23.7.934

[40] Nakahara, R., Yoshiuchi, K., Kumano, H., Hara, Y., Suematsu, H. and Kuboki T. (2006) Prospective Study on Influence of Psychosocial Factors on Glycemic Control in Japanese Patients with Type 2 Diabetes. Psychosomatics, 47, 240-246. http://dx.doi.org/10.1176/appi.psy.47.3.240

[41] Richardson, L.K., Egede, L.E., Mueller, M., Echols, C.L. and Gebregziabher, M. (2008) Longitudinal Effects of Depression on Glycemic Control in Veterans with Type 2 Diabetes. General Hospital Psychiatry, 30, 509-514. http://dx.doi.org/10.1016/j.genhosppsych.2008.07.001

[42] Weinger, K., Butler, H.A., Welch, G.W. and La Greca, A.M. (2005) Measuring Diabetes Self-Care. Diabetes Care, 28, 1346-1352. http://dx.doi.org/10.2337/diacare.28.6.1346

[43] Toobert, D.J., Hampson, S.E. and Glasgow, R.E. (2000) The Summary of Diabetes Self-Care Activities Measure: Results from 7 Studies and a Revised Scale. Diabetes Care, 23, 943-950. http://dx.doi.org/10.2337/diacare.23.7.943

[44] Cohen, H.W., Shmukler, C., Ullman, R., Rivera, C.M. and Walker, E.A. (2010) Measurements of Medication Adherence in Diabetic Patients with Poorly Controlled $\mathrm{HbA}_{1 \mathrm{c}}$. Diabetic Medicine, 27, 210-216. http://dx.doi.org/10.1111/j.1464-5491.2009.02898.x

[45] Raum, E., Kramer, H.U., Ruter, G., Rothenbacher, D., Rosemann, T., Szecsenyi, J. and Brenner, H. (2012) Medication Non-Adherence and Poor Glycaemic Control in Patients with Type 2 Diabetes Mellitus. Diabetes Research and Clinical Practice, 97, 377-384. http://dx.doi.org/10.1016/j.diabres.2012.05.026

[46] De-Nour, A.K. and Czackes, J.W. (1976) The Influence of Patient's Personality on Adjustment to Chronic Dialysis. The Journal of Nervous and Mental Disease, 162, 323-333. http://dx.doi.org/10.1097/00005053-197605000-00003

[47] Gonzalez, J.S., Safren, S.A., Cagliero, E., Wexler, D.J., Delahanty, L., Wittenberg, E., Blais, M.A., Meigs, J.B. and Grant, R.W. (2007) Depression, Self-Care, and Medication Adherence in Type 2 Diabetes: Relationships across the Full Range of Symptom Severity. Diabetes Care, 30, 2222-2227. http://dx.doi.org/10.2337/dc07-0158

[48] Gonzalez, J.S., Delahanty, L.M., Safren, S.A., Meigs, J.B. and Grant, R.W. (2008) Differentiating Symptoms of Depression from Diabetes-Specific Distress: Relationships with Self-Care in Type 2 Diabetes. Diabetologia, 51, 18221825. http://dx.doi.org/10.1007/s00125-008-1113-x

[49] Peyrot, M.F. and Rubin, R.R. (1997) Levels of Risks of Depression and Anxiety Symptomatology among Diabetic Adults. Diabetes Care, 20, 585-590. http://dx.doi.org/10.2337/diacare.20.4.585

[50] Rezvanfar, M.R., Salehi, B., Rafiee, M. and Shirian, F. (2009) Correlation of HbA1c and Major Depressive Disorder in Type 2 Diabetic Patients. Iranian Journal of Diabetes and Obesity, 2, 16-19.

[51] Harris, M.D. (2003) Psychosocial Aspects of Diabetes with an Emphasis on Depression. Current Diabetes Reports, 3, 49-55. http://dx.doi.org/10.1007/s11892-003-0053-6 
Scientific Research Publishing (SCIRP) is one of the largest Open Access journal publishers. It is currently publishing more than 200 open access, online, peer-reviewed journals covering a wide range of academic disciplines. SCIRP serves the worldwide academic communities and contributes to the progress and application of science with its publication.

Other selected journals from SCIRP are listed as below. Submit your manuscript to us via either submit@scirp.org or Online Submission Portal.
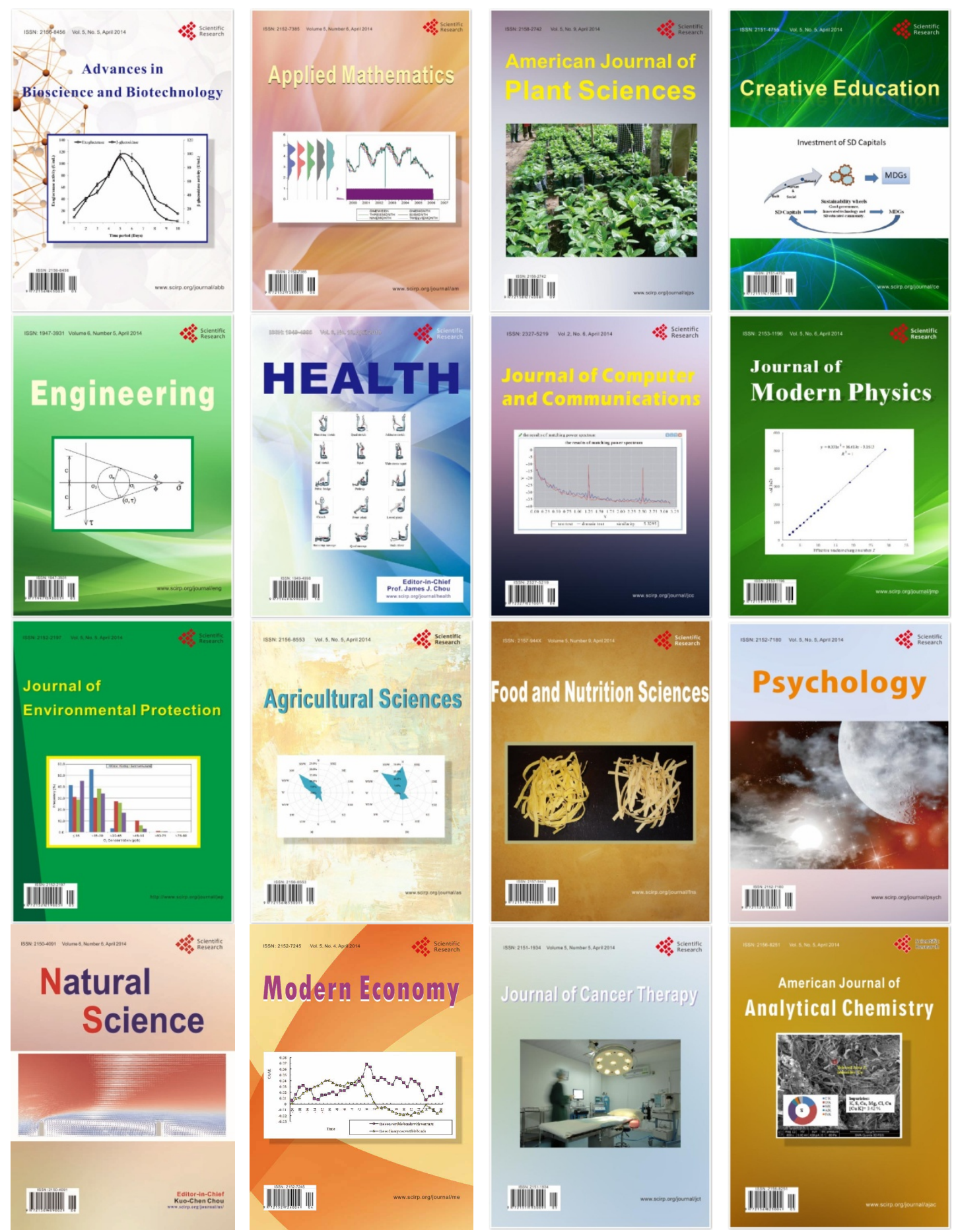